\title{
The CFD Analysis of Turbulence Characteristics in Combustion Chamber with Non Circular Co-Axial Jets
}

\author{
N L Narasimha Reddy ${ }^{1}$, P Manivannan ${ }^{2}$ and K M Kiran Babu ${ }^{3}$ \\ ${ }^{I}$ (Aeronautical Engineering, Hindustan University, Chennai, India) \\ ${ }^{2}$ (Aeronautical Engineering, Hindustan University, Chennai, India) \\ ${ }^{3}$ (Aeronautical Engineering, Hindustan University, Chennai, India)
}

\begin{abstract}
Co-Axial jets have applications in areas where the mixing of two fluid jets are necessary, the two fluid jets can be effectively mixed by producing the turbulence flow. Turbulence is a chaotic behavior of the fluid particles that comes in to picture when the inertia force of the flow dominates the viscous force and it is characterized by the Reynolds Number. Co-axial jets are effective in producing the turbulence. In the present study the free compressible turbulent coaxial jet problem will be computed using CFD, and compare with different non circular coaxial jets based on constant hydraulic diameter and mass flow rate. Turbulence characteristics of combustion chamber with circular coaxial and non circular coaxial jets are determined and compared.
\end{abstract}

Keywords: Coaxial Jet, Turbulence Modeling, Fuel injector, Combustion chamber.

\section{INTRODUCTION}

Extensive research into noncircular jets has been performed in the past two decades or so, largely due to their potential to entrain ambient fluid more effectively than comparable circular jets. The superior mixing capability of such jets is experimentally related either to the non-uniform curvature or their initial parameter, relative to the evenness for the circular configuration, or to the instabilities produced by the initial perimeter's sharp corners through the asymmetric distribution of pressure and mean flow field ${ }^{[17]}$. Both phenomena are deduced to accelerate three- dimensionality of the jet structures, therefore causing greater entraining and mixing. For elliptic and rectangular jets, azimuthal curvature variation of initial vortical structure produces non-uniform self-induction and three-dimensional structures. As a result, these flows spread more rapidly in the minor axis plane than in the major axis plane, causing "axis switching" at a certain distance from the nozzle exit. ${ }^{[17]}$, For corner containing configurations, the corners promote the formation of fine scale mixing ${ }^{[6,8]}$. The above experimental results have also been demonstrated in a number of numerical simulations. ${ }^{[13,14,15]}$. The review of Gutmark and Grinstein ${ }^{[17]}$ summarizes both experimental and numerical studies in the context of non-circular jets. Note however that previous investigations on noncircular jets, ${ }^{[2-3,5-8,10,13-15,17,19]}$, have focused, predominantly on elliptical, rectangular (including square), and triangular configurations. Few detailed measurements and simulations have been performed on the different coaxial jets were shown for other shapes ${ }^{[2-}$ $3,5-8,10,13-15,17,19]$

The present study carried out the turbulence measurements of three jets issuing respectively from Circular, Square and Hexagonal form orifice with equivalent hydraulic diameter. The main objective of the present work is using the CFD results, to compare the turbulent flow fields of the three jets to identify their similarity and difference.

\subsection{Fuel Injector}

\section{DISCRIPTION OF THE PROBLEM}

Fuel injection is a necessary component for all high performance engines because the fuel to air ratio must be precisely controlled due to the extreme temperature and pressures found in high-compression turbo engines. Combine this with large displacement and multiple cylinder power plants and the standard carburetor arrangement simply cannot deliver a precisely controlled fuel-air mix to all cylinders simultaneously.

For smaller engines, inlet-port fuel injection can increase the power output of an engine by merely reducing the temperature of the air charge, thereby increasing the density of the fuel and air mix. In most cases a 10 percent increase in power is achieved without any change to compression ratios or engine RPM; something a carburetor just can't do.

On engines where fuel is injected directly into the combustion chamber, the resulting spray pattern has a huge impact on the burn rate of the charge and the usefulness of the expanding flame-front. Fuel injected in this manner is better utilized if the entire combustion chamber is saturated with an atomized charge of fuel and air. For this reason, some large diesel engines use nozzles with two to 16 separate holes designed to provide a spray pattern that burns hotter and results in more complete combustion. Although efficient, the complexity of this 
system remains unsuitable for aviation use. However, the need for a consistent spray pattern - even from our single-point nozzle - remains vitally important. Modeling of fuel injectors has been done in ANSYS design modeler. Inner jet diameter is assumed and modeled for different shaped based on hydraulic diameter. Hydraulic diameter is mathematically represented as follow:

$$
d_{h}=\frac{4(\text { Cross }- \text { Sectional Area })}{\text { Perimeter }}, \mathrm{mm} \text {. }
$$

\subsection{Combustion Chamber}

The working fluid in the engine is heated by an internal combustion process. Before this chemical reaction can occur, the liquid fuel must be injected into the airstream, atomized and the vapor must be mixed with the air. Space is of course at a premium in aircraft applications, so that great effort is made to reduce the size of the combustion chamber by hastening completion of the above processes. To keep engine size small, the intensity of combustion (measured in, e.g. $\mathrm{KJ} / \mathrm{m}^{3} \mathrm{~s}$ ) must be as high as possible. The combustion rate in gas turbines at sea level is of the order of $500,000 \mathrm{~kJ} / \mathrm{m}^{3} \mathrm{~s}$, which is more than 100 times as intense as the combustion in a large stationary power plant furnace. Part of the reason for the difference is that in the gas turbine the density of the reactants is perhaps 10 times as high as in an atmospheric pressure furnace. Part of the reason is the fineness of atomization of the injected fuel and another part is the intensity of the turbulence in a typical gas turbine combustor. The more intense of turbulence leads to rapid mixing of the vaporized fuel and air and the faster propagation of flame through the unburned mixture. Before considering typical designs of combustors for air-breathing jet propulsion engines, we consider the combustion temperatures available with typical fuels.

\subsubsection{Combustion Temperature and Fuel -Air Ratio}

Table 1 shows the properties of fuels commonly used in gas turbine combustors. Each fuel is a mixture of hydrocarbon compounds, and the mixture composition is variable to some extent. Table 1 therefore provides representative (rather than exact) properties typical of the mixtures that fall within the specification limits for each fuel. JP -4 fuel is relatively volatile and so has high vapor pressure.

$\mathrm{JP}-4$ and Jet A are widely used fuels for turbines. Aviation kerosene is not in plentiful supply.

For approximate calculation of fuel - air ratio and combustion temperature we can describe these fuels as having hydrogen - carbon ratios of 2 and lower heating values (LHV) of 43,400 kJ/kg. Then, treating the turbojet combustion process as through it were a heating process, we can write.

$\dot{m}_{f} Q_{R}=\dot{m}_{a} C_{p}\left(T_{04}-T_{03}\right)$,

Where $\dot{m}_{f}$ is the fuel flow rate, $\dot{m}_{a}$ is the air flow rate, and $C_{p}$ is the specific heat at constant pressure. In terms of the fuel - air ratio $f=\dot{m}_{f} / \dot{m}_{a}$.

$f=\frac{C_{p}}{Q_{R}}\left(T_{04}-T_{03}\right)$.

\section{RESULTS AND DISCUSSION}

Fuel injector diameter is taken as $8 \mathrm{~mm}$ for single jet. It has been modeled using ANSYS DESIGN MODULAR. For coaxial circular jet, the diameter ratio (i.e. the ratio of the outer diameter to the inner diameter) is considered as 2, and the inner diameter as $4 \mathrm{~mm}$. Then the circular coaxial jet is designed based on the above values, in ANSYS DESIGN MODULAR as shown in figure 4.2.

To model non circular coaxial jets, inner cross section of the circular coaxial jet diameter is considered. The different cross section of the noncircular diameter is calculated using equation 1 (i.e. hydraulic diameter is ratio of 4 times of the cross sectional area to the perimeter). Based on this calculation, different models are designed. Fuel injector is placed in the combustion chamber perpendicular to the central axis. Fuel inlet 1 and fuel inlet 2 are mentioned on the basis of mass flow rate as calculated. Modeling of combustion chamber is done based on the project report ${ }^{[28]}$ with small changes in secondary cooling ports and primary inlet diameter. Air is passed through the primary inlet with the velocity of $25 \mathrm{~m} / \mathrm{s}$ (i.e. flow inside the combustion should have low velocity for proper combustion).

\subsection{Calculations}

Molar volume for 1 mole of substance at $1 \mathrm{~atm}$ pressure and temperature $25^{\circ} \mathrm{C} .=24.789 \mathrm{~L} / \mathrm{mol}$.

$V_{m}=\frac{M}{\rho} \mathrm{m}^{3} / \mathrm{mol}$

$$
=24.789 * 10^{-3} \mathrm{~m}^{3} / \mathrm{mol} \text {. }
$$

Where $V_{m}, M$ and $\rho$ are molar volume, molar weight and density respectively.

$M=58.12 \mathrm{~g} / \mathrm{mol}$. $\left\{\right.$ for $\left.\mathrm{C}_{4} \mathrm{H}_{10}\right\}$

$=\quad 32 \mathrm{~g} / \mathrm{mol} .\left\{\right.$ for $\left.\mathrm{O}_{2}\right\}$ 
Assume pressure $1.5 \mathrm{bar}$ for fuel injection and assume temp. $300 \mathrm{~K}$

From combine gas law

$\frac{P_{1} V_{m 1}}{T_{1}}=\frac{P_{2} V_{m 2}}{T_{2}}$

Therefore;

$\frac{1 * 24.789 * 10^{-3}}{298}=\frac{1.5 * V_{m 2}}{300}$

$V_{m 2}=0.0166 \mathrm{~m}^{3} / \mathrm{mol} .=\frac{58.12 * 10^{-3}}{\rho_{C_{4} H_{10}}}$

$\rho_{C_{4} H_{10}}=3.494 \mathrm{~kg} / \mathrm{m}^{3}$

$\rho_{O_{2}}=1.9242 \mathrm{~kg} / \mathrm{m}^{3}$ \{because $0.0166 \mathrm{~m}^{3} / \mathrm{mol} .=\frac{32 * 10^{-3}}{\rho_{C_{4} H_{10}}}$ \}

Calculation of single jet mass flow rate:

$$
\begin{aligned}
\dot{m}_{f}=A * \sqrt{2 * P * \rho}, \mathrm{kg} / \mathrm{s} . \\
=\frac{\pi *\left(8 * 10^{-3}\right)^{2}}{4} * \sqrt{2 * 1.5 * 10^{5} * 3.494}, \mathrm{~kg} / \mathrm{s} . \\
=0.05146, \mathrm{~kg} / \mathrm{s} .
\end{aligned}
$$

Calculation of Co-axial\{circle -circle $\}$ jet mass flow rate:

$$
\begin{aligned}
\dot{m}_{f_{O_{2}}} & =\frac{\pi *\left\{\left(8 * 10^{-3}\right)^{2}-\left(4.3 * 10^{-3}\right)^{2}\right\}}{4} * \sqrt{2 * 1.5 * 10^{5} * 1.9242}, \mathrm{~kg} / \mathrm{s} . \\
& =0.0271 \mathrm{~kg} / \mathrm{s} . \\
\dot{m}_{f_{C_{4} H_{10}}} & =\frac{\pi\left(4 * 10^{-3}\right)^{2}}{4} * \sqrt{2 * 1.5 * 10^{5} * 3.494}, \mathrm{~kg} / \mathrm{s} . \\
& =0.0128 \mathrm{~kg} / \mathrm{s} .
\end{aligned}
$$

Calculation of Co-axial \{circle -square\} jet mass flow rate:

$$
\begin{array}{lll}
\dot{m}_{f_{O_{2}}} & = & \left\{\frac{\pi *\left\{\left(8 * 10^{-3}\right)^{2}\right\}}{4}-\left(4.3 * 10^{-3}\right)^{2}\right\} * \sqrt{2 * 1.5 * 10^{5} * 1.9242}, \mathrm{~kg} / \mathrm{s} . \\
\dot{m}_{f_{C_{4} H_{10}}} & = & 0.0241 \mathrm{~kg} / \mathrm{s} . \\
& = & \left(4 * 10^{-3}\right)^{2} * \sqrt{2 * 1.5 * 10^{5} * 3.494}, \mathrm{~kg} / \mathrm{s} .
\end{array}
$$

Calculation of Co-axial \{circle -hexagonal\} jet mass flow rate:

$$
\begin{array}{lll}
\dot{m}_{f_{O_{2}}} & = & \left\{\frac{\pi *\left\{\left(8 * 10^{-3}\right)^{2}\right\}}{4}-\frac{3 \sqrt{3} *\left(2.48 * 10^{-3}\right)^{2}}{2}\right\} * \sqrt{2 * 1.5 * 10^{5} * 1.9242}, \mathrm{~kg} / \mathrm{s} . \\
& = & 0.02605 \mathrm{~kg} / \mathrm{s} . \\
\dot{m}_{f_{C_{4} H_{10}}} & = & \frac{3 \sqrt{3} *\left(2.31 * 10^{-3}\right)^{2}}{2} * \sqrt{2 * 1.5 * 10^{5} * 3.494}, \mathrm{~kg} / \mathrm{s} . \\
& = & 0.01419 \mathrm{~kg} / \mathrm{s} \approx 0.0142 \mathrm{~kg} / \mathrm{s} .
\end{array}
$$

After giving these parameters in CFX - Pre processer (Setup), results are obtained in the CFX - Post processor (Result). From the result we found the values for velocity variations, turbulence kinetic energy, turbulence eddy dissipation and etc. Variations of these parameters along the axial length are shown in chart 4.1, 4.2 and 4.3 respectively. We found that turbulence kinetic energy is more for noncircular coaxial (circle hexagonal) jet than circular coaxial jet and single jet (except circle - square cross section). From above graphs or charts we found that turbulence eddy dissipation is low for circle - square cross section when used as a fuel injector as compared to circle - hexagonal and circle - circle.

Turbulence kinetic energy for circle - hexagonal fuel injector instead of circle - circle, circle - square, and single jet shows $20.3 \%, 30.2 \%$, and $85.9 \%$ is more at the $0.06 \mathrm{~cm}$ of axial length respectively.

Turbulence eddy dissipation profile is shown in chart 4.3 along the axial length. It is found that turbulence eddy dissipation of circle - hexagonal is high as compared to other coaxial jets as well as single jet when they used as the fuel injectors. The percentage rise in turbulence eddy dissipation when used circle hexagonal shaped coaxial fuel injector as compared to others (proposed shapes are circle - circle, circle - square and single jets ) are $17.6 \%, 42.7 \%$ and $99.7 \%$ respectively. 


\section{FIGURES AND TABLES}

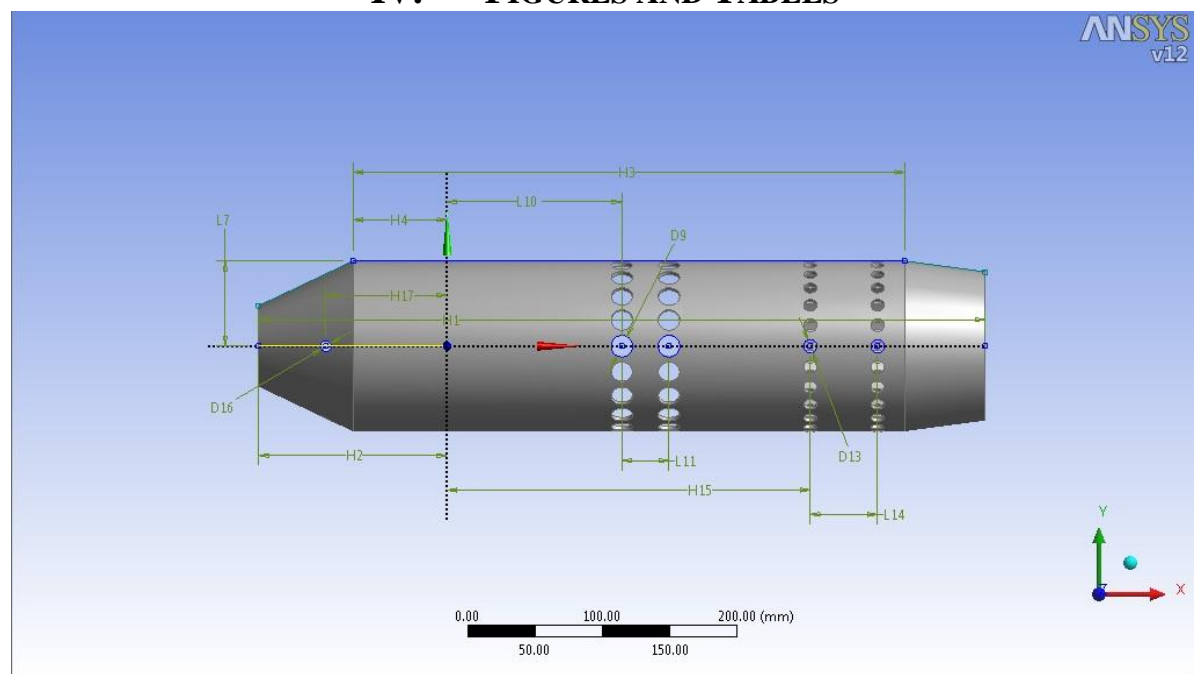

Fig 4.1: Can type combustion chamber

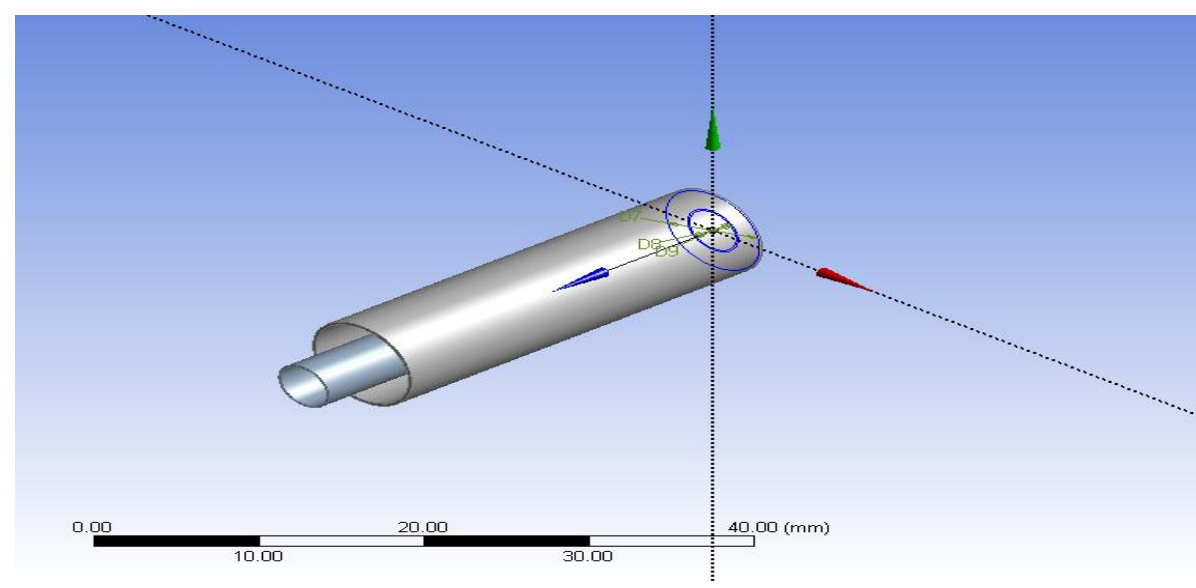

Fig 4.2: Circle - Circle injector model

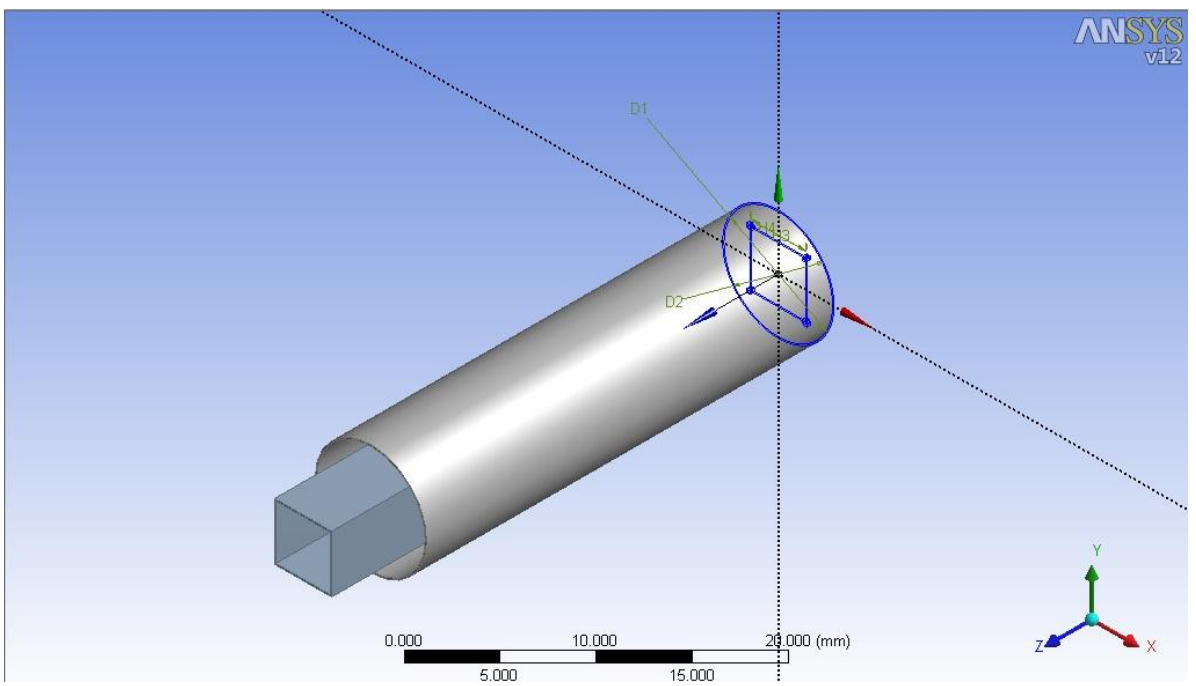

Fig 4.3: Circle - Square injector model 


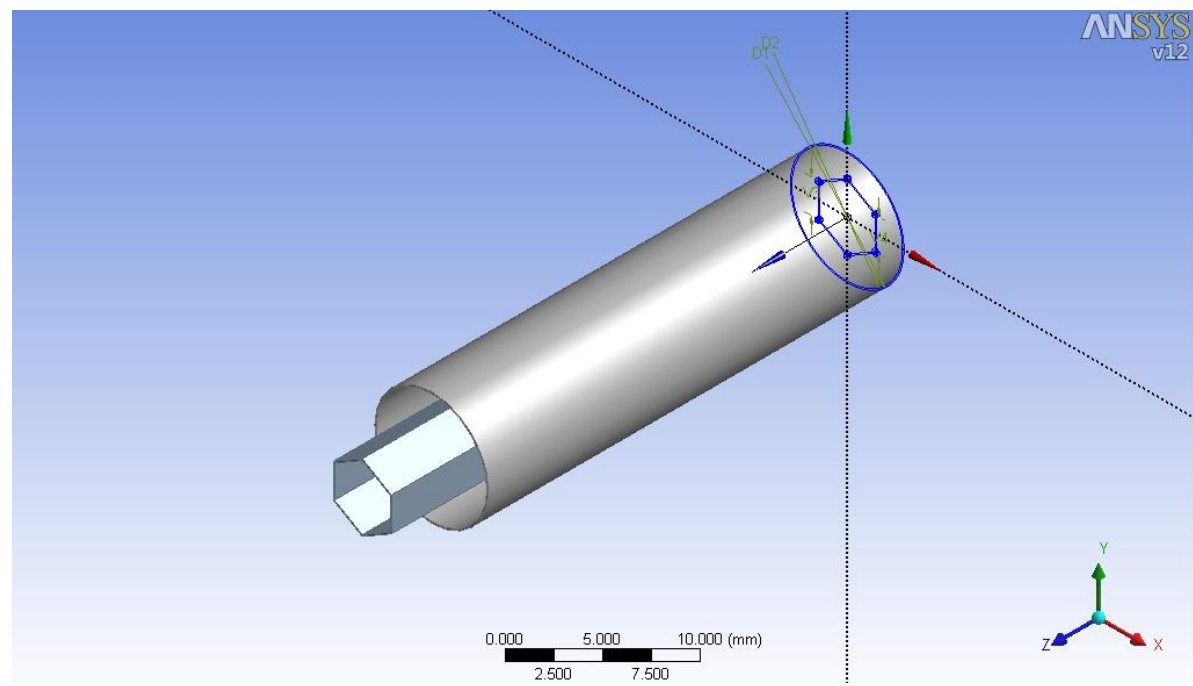

Fig 4.4: Circle - hexagonal injector model

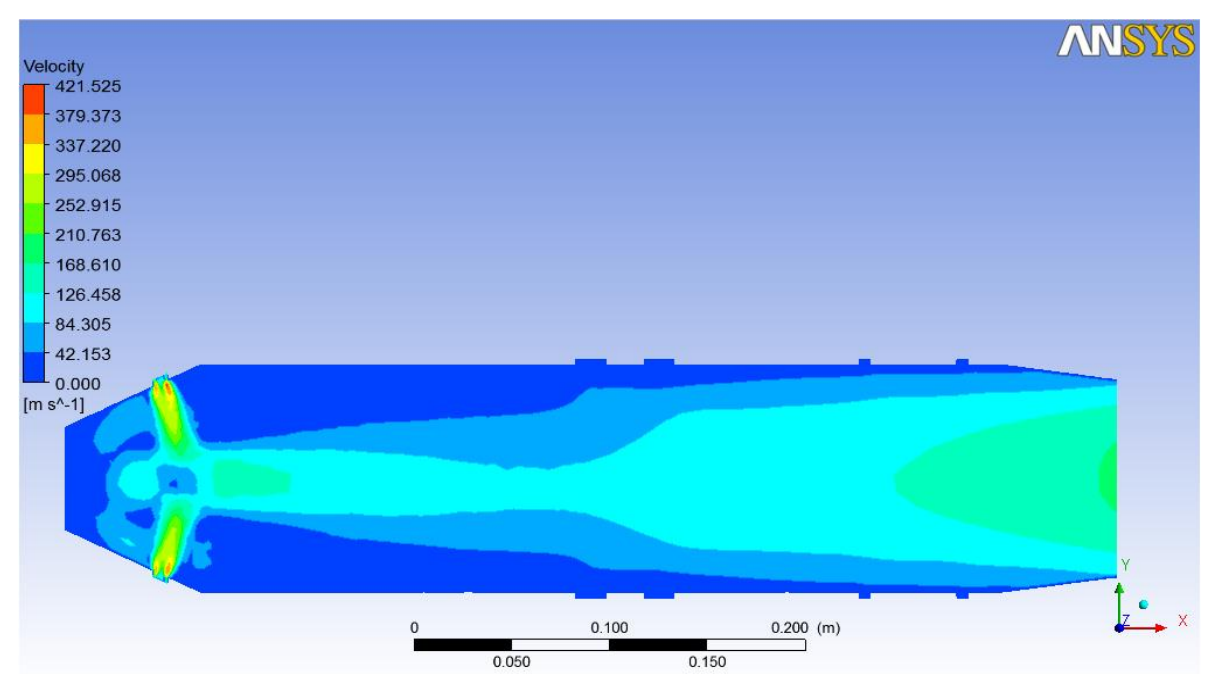

Fig 4.5: velocity variation in combustion chamber for circular co - axial fuel injector

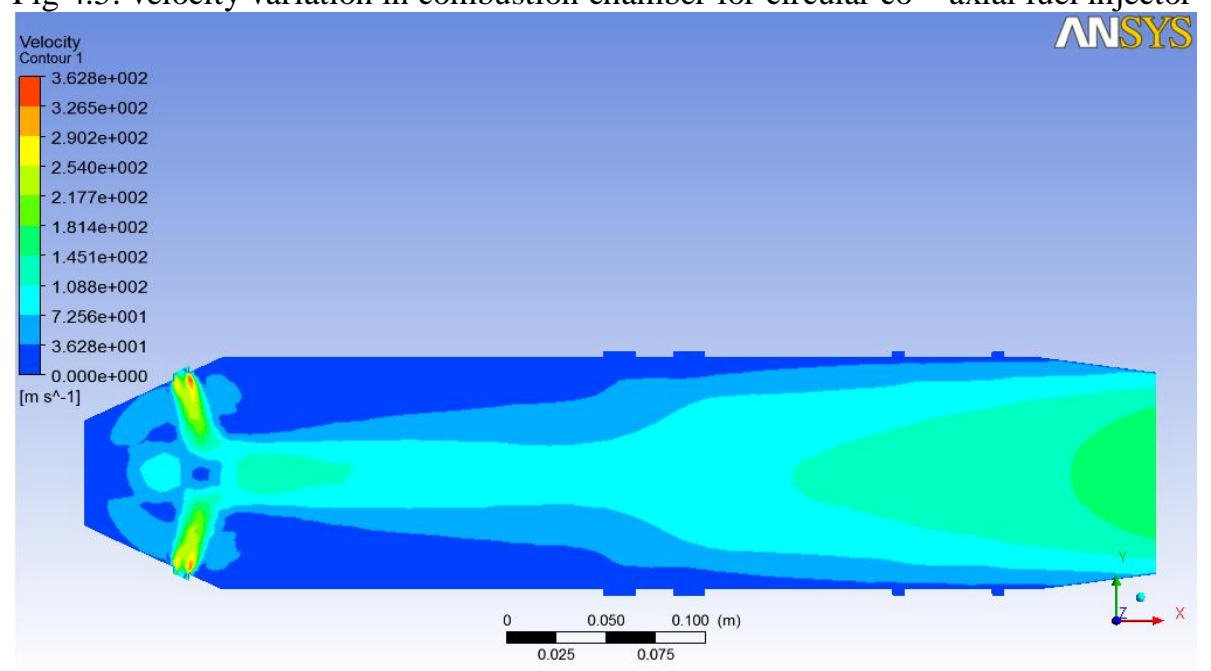

Fig 4.6: velocity variation in combustion chamber for circle - square coaxial fuel injector 


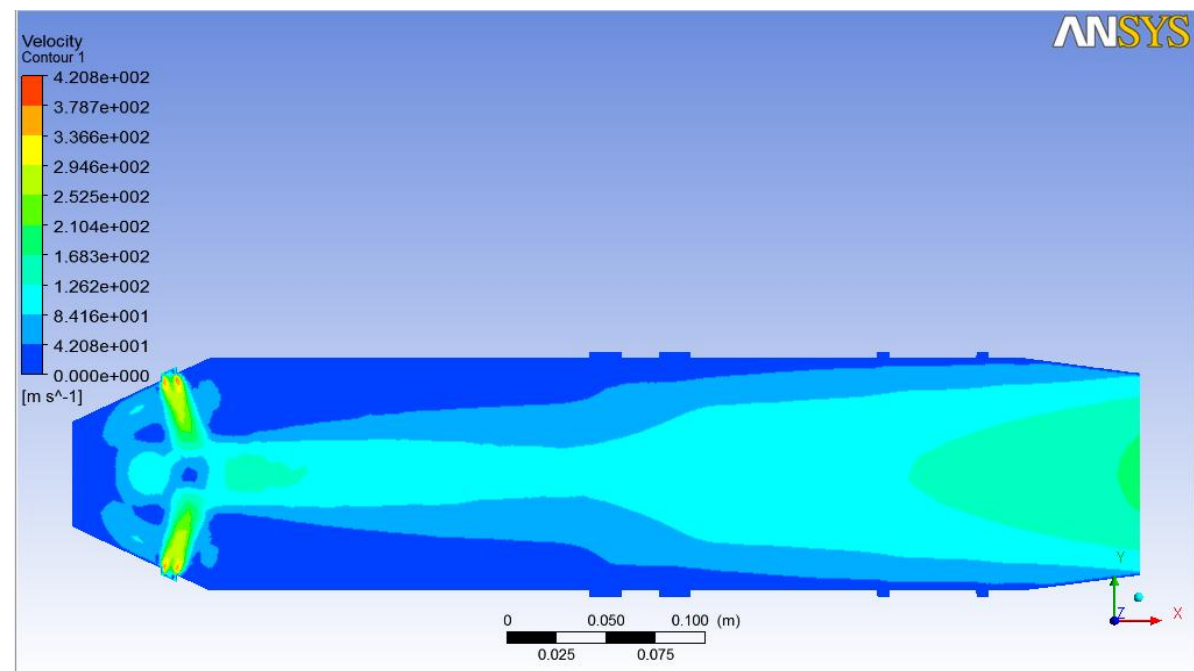

Fig 4.7: velocity variation in combustion chamber for circle - hexagonal coaxial fuel injector

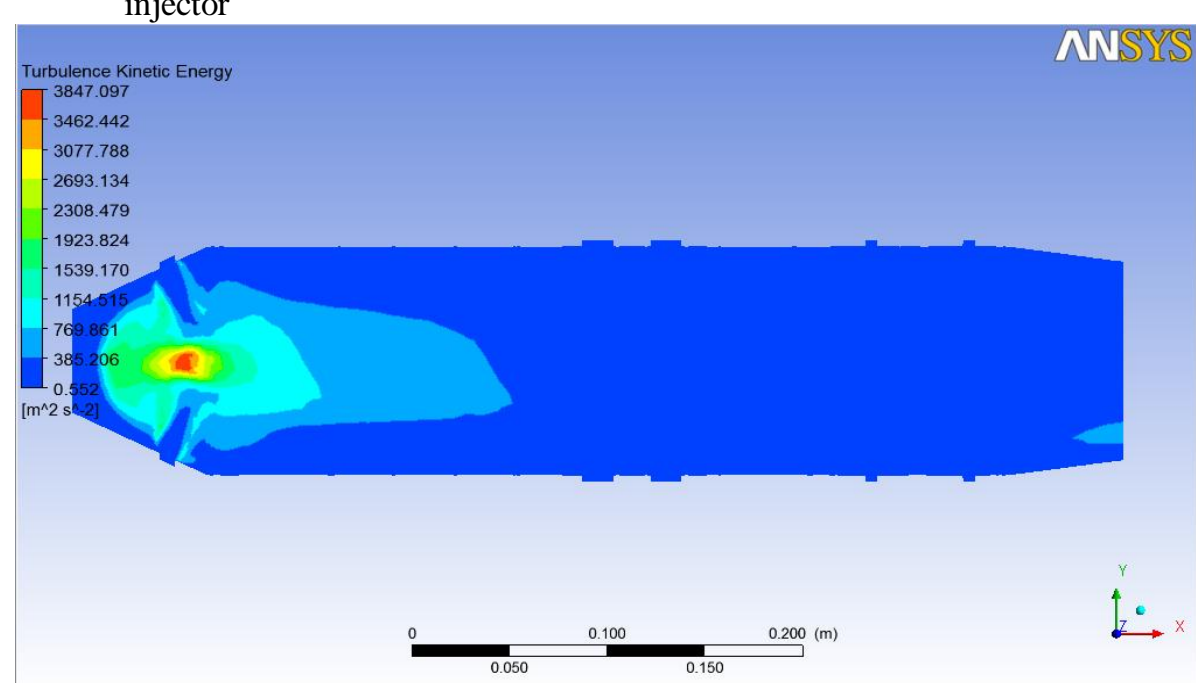

Fig 4.8: Turbulence Kinetic Energy variation in combustion chamber for circular coaxial fuel injector

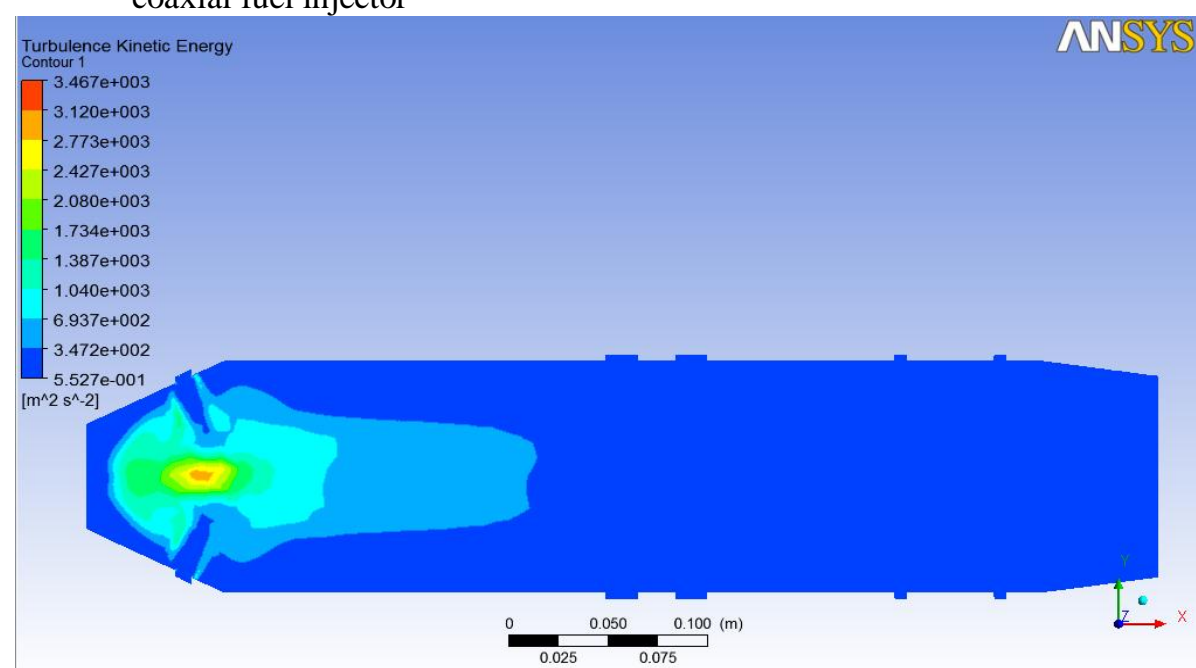

Fig 4.9: Turbulence Kinetic Energy variation in combustion chamber for circle -square co - axial fuel injector 


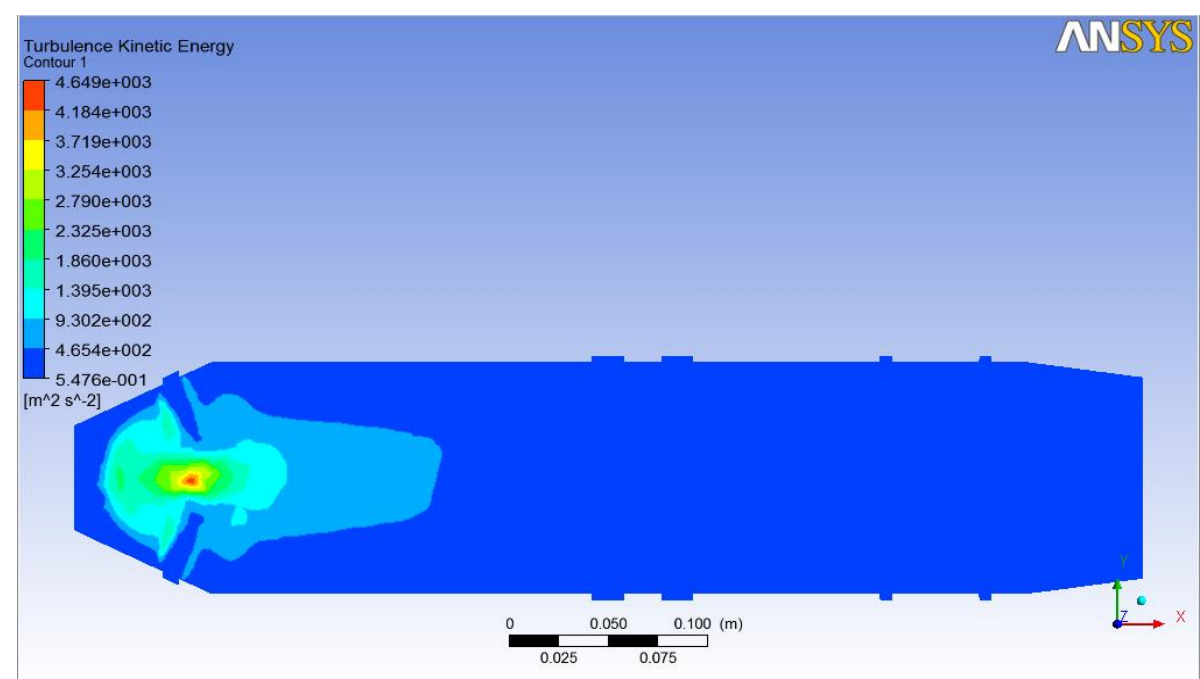

Fig 4.10: Turbulence Kinetic Energy variation in combustion chamber for circle - hexagonal coaxial fuel injector

Table 4.1: Dimensions of Can type combustion chamber

\begin{tabular}{|c|c|c|}
\hline S.No. & Parameters & Dimensions \\
\hline 1 & H1 & $540 \mathrm{~mm}$ \\
\hline 2 & H2 & $140 \mathrm{~mm}$ \\
\hline 3 & H3 & $410 \mathrm{~mm}$ \\
\hline 4 & H4 & $070 \mathrm{~mm}$ \\
\hline 5 & H15 & $270 \mathrm{~mm}$ \\
\hline 6 & H17 & $090 \mathrm{~mm}$ \\
\hline 7 & D9 & $16 \mathrm{~mm}$ \\
\hline 8 & D13 & $10 \mathrm{~mm}$ \\
\hline 9 & D16 & $08 \mathrm{~mm}$ \\
\hline 10 & L7 & $063 \mathrm{~mm}$ \\
\hline 11 & L10 & $130 \mathrm{~mm}$ \\
\hline 12 & L11 & $035 \mathrm{~mm}$ \\
\hline 13 & L14 & $050 \mathrm{~mm}$ \\
\hline
\end{tabular}

Table 4.2: properties of fuel commonly used in gas turbines

\begin{tabular}{|c|c|c|c|c|c|}
\hline S.No. & Property & $\begin{array}{l}\text { Aviation } \\
\text { Kerosene }\end{array}$ & $\mathrm{JP}-4$ & $\mathrm{JP}-5$ & Jet A \\
\hline 1 & H-C Ratio & 1.93 & 2.02 & 1.92 & 1.94 \\
\hline 2 & $\begin{array}{l}\text { Vapor press at } 38^{\circ} \mathrm{C}, \\
\mathrm{kPa} .\end{array}$ & & 18 & 0.3 & 0.7 \\
\hline 3 & $\begin{array}{l}\text { Initial boiling point, } \\
{ }^{\circ} \mathrm{C} .\end{array}$ & 50 & 60 & 180 & 170 \\
\hline 4 & End point,${ }^{\circ} \mathrm{C}$ & 260 & 246 & 260 & 265 \\
\hline 5 & Flash point, ${ }^{\circ} \mathrm{C}$ & & -25 & 65 & 52 \\
\hline 6 & L.H.V,kJ/kg & 43,200 & 43,400 & 43,000 & 43,400 \\
\hline 7 & Density, $\mathrm{kg} / \mathrm{m}^{3}$ & 800 & 760 & 820 & 810 \\
\hline 8 & $\begin{array}{l}\text { Stoich,fuel - air mass } \\
\text { ratio }\end{array}$ & 0.0679 & 0.0673 & 0.0680 & 0.0678 \\
\hline 9 & $\begin{array}{l}\text { Stoich, air - fuel } \\
\text { mass ratio }\end{array}$ & 14.72 & 14.85 & 14.71 & 14.74 \\
\hline
\end{tabular}




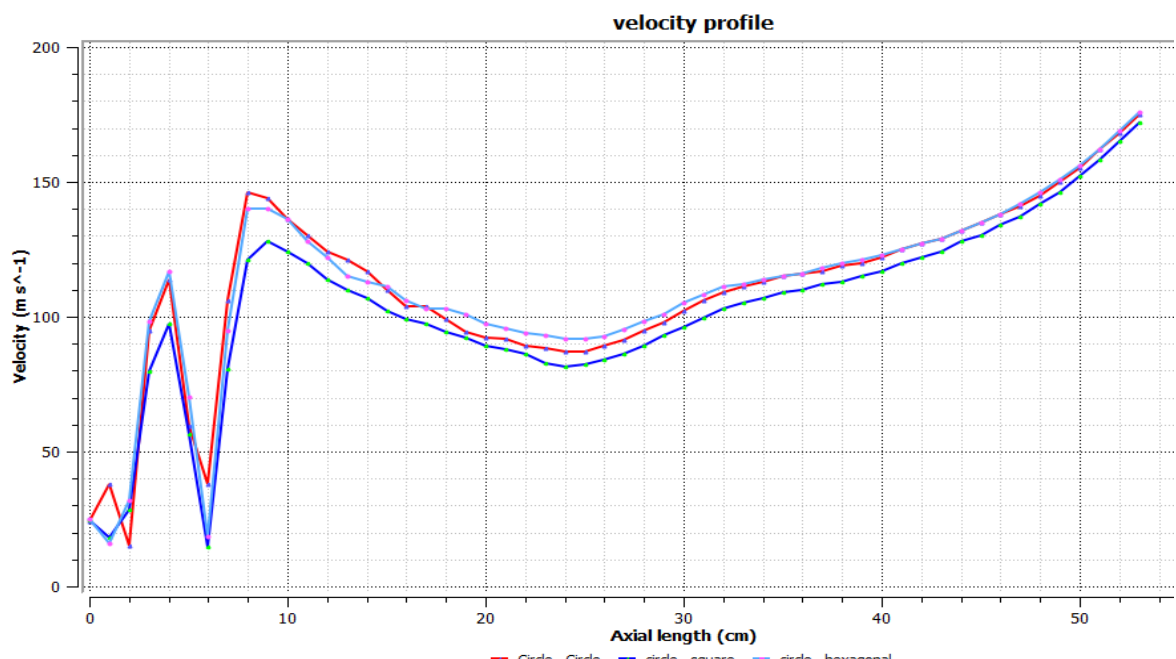

Chart 4.1: Velocity profile along axial length

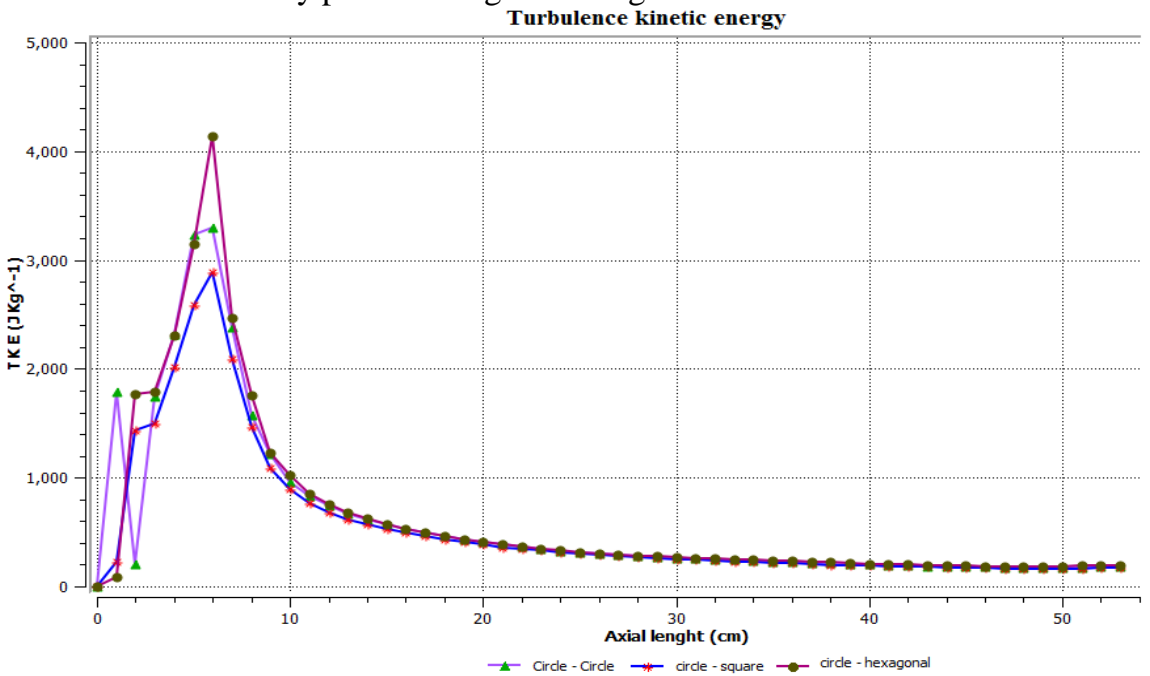

Chart 4.2:turbulence kinetic energy profile along axial length

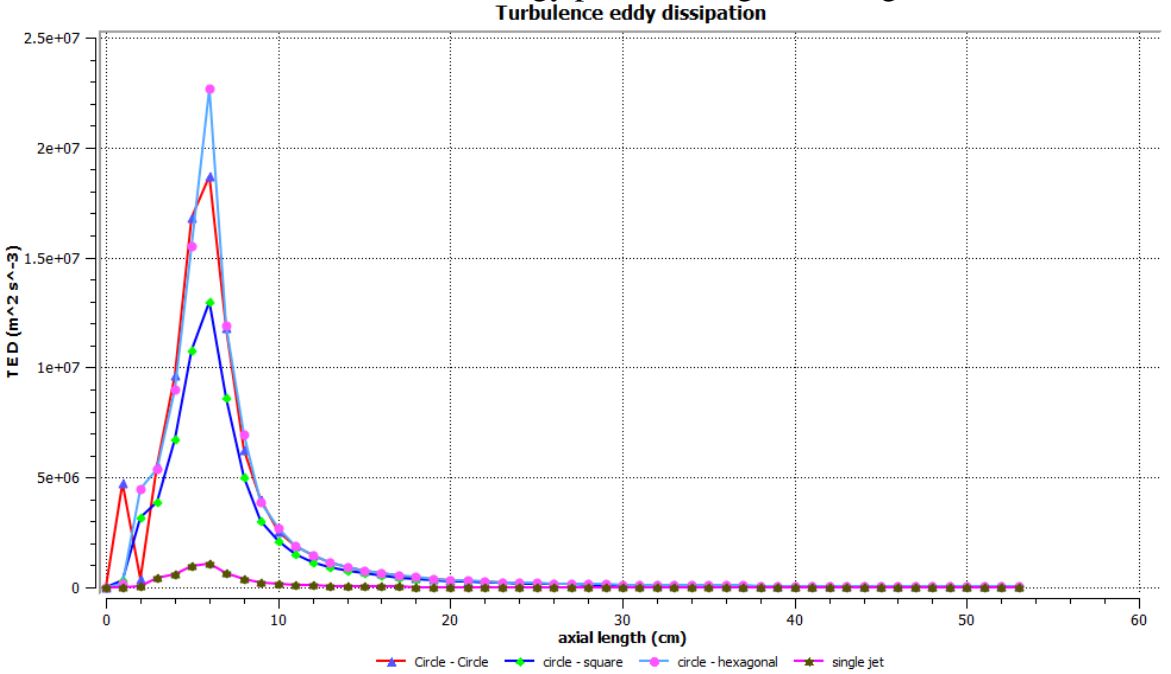

Chart 4.3:turbulence kinetic energy profile along axial length

\section{CONCLUSION}

Modeling of co-axial fuel injector (circular and non circular) based on hydraulic diameter of single jet fuel injector of combustion chamber. Analysis on these modeled shapes has been done based on mass flow rate. Obtained results shown a good turbulence kinetic energy in non - circular shape compared to circular shape except circle - square one (proposed shapes). Turbulence characteristics such as turbulence eddy dissipation, 
turbulence kinetic energy, and velocity profiles are shown in above graph along the axial length. The main drawback in this is it's not providing good turbulence kinetic energy and turbulence eddy dissipation in Circle Square shape as compare with circular coaxial jet used as fuel injector. Where else Circle - Hexagonal shape produce $20.3 \%$ and $17.6 \%$ more turbulence kinetic energy and turbulence eddy dissipation respectively than circular coaxial jet.

\section{ACKNOWLEDGEMENTS}

It is a great pleasure to be able to show our faithful thanks to many people who helped and greatly supported us during writing of this thesis.

First \& foremost, I wish to express our utmost gratitude to our Chairperson Dr. ELLZABETH VERGHESE \& Dr. JOSEPH STANLEY, Director (Academic) for granting us to attend this project at HINDUSTAN INSTITUTE OF TECHNOLOGY AND SCIENCE, CHENNAI.

I am grateful to Prof. NAGARAJAN M.E, (HOD) Department of Aeronautical engineering for his encouragement, discussion and helpful attitude.

I extend our heartfelt gratitude goes to our Internal Guide Mr. P. MANIVANNAN, Asso. Prof. for his technical contributions, valuable comments and many innovative ideas to carrying out this project. Without his timely help it would have been impossible for us to complete this work.

I most sincerely acknowledge the staff members of Department of Aeronautical Engineering for their constant inspiration and suggestions.

Last but not the least; I would like to thank my parents and my siblings for their support throughout my life.

\section{REFERENCES}

[1] F. H. Champagne and I. J. Wygnanski, An experimental investigation of coaxial turbulent jets, Int. J. Heal Mass Transfer. Vol. 14, pp. 1445 - 1464, Pergamon Press 1971.

[2] Krothapalli, A ., Baganoff,D. \& Karamchheti,K., On the mixing of Rectangulat jets. Journal of Fluid Mechanics.107,1981,pp201220 .

[3] Husain H.S. \& Hussain F., Controlled excitation of elliptic jets Physics of Fluids, 26, 1983, pp2763-2766.

[4] P. Givi and J.I. Rsmos, On The calculation of heat, mass and momentum tansport in coaxial jets and mixing layers, Int. CCMM. Heat Mass Transfer Vol. 12, pp. 323 - 336, Pergamon Press 1985.

[5] Ho, C.M. \& Gutmark, E., Vortex induction and mass entrainment in a small-aspect-ratio elliptic jet, Journal of Fluid mechanics. $179,1987, \mathrm{pp} 383-405$.

[6] Gutmark, E., Schadow, K.C., Parr, T.P., Hanson-Parr, D.M., \& Wilson, K.J., Noncircular jets in combustion systems, Experiments in Fluids 7, 1989,pp248-258.

[7] Hussain F, Husain H.S, Elliptic jets Part 1. Characteristics of unexcited and excited jets. Journal of Fluid mechanics,208, 1989, pp 257-320.

[8] Koshigoe,S.,Gutmark, E \& Shadow, K., Initial Development of Non-circular jet leading to axis switching. AAIA Jr. 27,1989, pp439.

[9] S. Ushijima, N. Tanaka and S. Moriya, Turbulence measurements and calculations of non-isothermal coaxial jets, Nuclear Engineering and Design 122, pp. 85 - 94, Elsevier Science Publishers 1990.

[10] Husain H.S, Hussain F, Elliptic jets Part 2. Dynamics of coherent structures: paring, Journal of Fluid Mechanics, 233,1991, pp439.

[11] A.E. Bakry, A study of the upstream influence on the near field of an axisymmetric jet using LDA. M.Sc. thesis, Faculty of Engineering, Alexandria University, 1992.

[12] Guido Buresti, Alessandro Talamelli and Paolo Petagna, Experimental characterization of the velocity field of a coaxial jet configuration, Experimental Thermal and Fluid Science, pp.135 - 146, Elsevier Science Publishers 1994.

[13] Grinstein, F.F., Self-induced vortex ring dynamics in subsonic rectangular jets. Phys. Fluids 7, 1995, pp2519-2521.

[14] Grinstein, F.F., Gutmark, E. and Parr, T., Near field dynamics of subsonic free square jets, A computational and experimental study, Phys. Fluids, 7,1995, pp1483-1497.

[15] Miler, R.S., Madnia, C.K. \& Givi.P., Numerical Simulations of non- circular jets , Computers\& Fluids 24, 1995, pp1-25.

[16] Philippe Reynier and Hieu Ha Minh, Numerical prediction of unsteady Compressible turbulent coaxial jets, Computers \& Fluids Vol. 27, No. 2, pp. 239 - 254, Pergamon Press 1998.

[17] Gutmark, E. \& Grinstein, F.F., Flow control with noncircular jets. Ann. Rev. Fluid Mech., 31, 1999, pp239-272.

[18] H.A. Warda, S.Z. Kassab, K.A. Elshorbagy and E.A. Elsaadawy, An experimental investigation of the near-field region of free turbulent round central and annular jets, Flow Measurement and Instrumentation 10, pp. 1-14, Elsevier Science Publishers 1999.

[19] Mi,J. Nathan,G.J, and Luxton,R.E., Centreline mixing characteristics of jets from nine differently shaped nozzles, Experiments of Fluid 28,2000,pp93-94

[20] T. Yilmaz and A. Kodal, An analysis on coaxial jet flows using different decomposition techniques, Journal of Fluids and Structures 14, pp. 359 - 373, Academic Press 2000.

[21] H.A. Warda, S.Z. Kassab, K.A. Elshorbagy and E.A. Elsaadawy, Influence of the magnitude of the two initial velocities on the flow field of a coaxial turbulent jet, Flow Measurement and Instrumentation 14, pp. 29-35, Elsevier Science Publishers 2001.

[22] Wassim Kriaa, Hatem Mhiri, Georges Le Palec and Philippe Bournot, Numerical study of the interaction between two laminar and coaxial plane jets with variable density in an ambient fluid, Energy Conversion and Management 44, pp. 2037-2057, Pergamon Press 2003.

[23] Victor Piffaut ,Axis-Switching in square coaxial jets, M.Sc., thesis, Louisiana State University and Agricultural and Mechanical College, 2003.

[24] Seong Ryong Koh, Wolfgang Schroder and Matthias Meinke, Turbulence and heat excited noise sources in single and coaxial jets, Journal of Sound and Vibration, pp. 1 - 18, Elsevier Science Publishers 2009.

[25] G. R. Stroher, C. A. Martins, and C. R. de Andrade, Numerical and experimental study of a free incompressible isothermal turbulent coaxial jet, Engenharia Térmica (Thermal Engineering), Vol. 9, No 01 e 02, pp. 98 - 107, 2010. 
[26] P. Manivannan, P.K. Dash and B.T.N. Sridhar, An experimental study on comparison of non - circular co - flow jet with Co - axial jets and computational verification, Space Research Journal 4 (2), pp. 60 -70, Academic Press 2011.

[27] Lars Davidson, An Introduction to Turbulence Models, Department Of Thermo And Fluid Dynamics ,Chalmers University Of Technology, pp. 1 - 48, 2011.

[28] S.Inbaraj, V.S.Mohan, G.Prabhakaran and V.Rahul, Flow Analysis Through A Combustor With and Without Perforated Plates By Using Methane As Fuel, Department Of Aeronautical Engineering, Sams College Of Engineering \& Technology, Anna University, Chennai, pp. $1-75,2012$.

Books:

[29] P. Hill and C. Peterson, Mechanics and Thermodynamics of Propulsion, Addison - Wesley Publishing Company, 1992.

[30] V. Ganesan, Gas Turbines, Tata McGraw Hill Publishing Co., New Delhi, 1999. 